\title{
APLICAÇÃO SUPERFICIAL DE CALCÁRIO EM POMAR DE LARANJEIRA PÊRA EM PRODUÇÃO'
}

\author{
MARCOS ANTONIO CAMACHO DA SILVA², WILLIAM NATALE ${ }^{3,4}$, RENATO DE MELLO PRADO $^{3,4}$, \\ MÁRCIO CLEBER MEDEIROS CORRÊA ${ }^{5}$, EDUARDO SANCHES STUCHI ${ }^{4,6}$, ITAMAR ANDRIOLI $^{3}$
}

RESUMO - A citricultura paulista é a maior do mundo, sendo de extrema importância manejos que visem a aumentar e melhorar a produção de frutos. Com vistas a isso, foi instalado na EECB (Bebedouro-SP), em um Latossolo Vermelho distrófico típico, um experimento com a aplicação de cinco doses de calcário calcinado, em julho/99. Os efeitos no solo foram avaliados através de amostragens nas camadas de $0-10 ; 10-20 ; 20-40$ e 40-60 cm, aos 6; 12; 18;24; 30 e 36 meses. Através da utilização de modelos lineares, constatou-se que os efeitos da aplicação superficial de calcário no solo podem atingir até a camada de $20-40 \mathrm{~cm}$, sendo a saturação por bases uma ótima característica indicadora da ação do corretivo. A máxima reação do calcário ocorreu entre 12 e 18 meses após a aplicação. O estado nutricional das plantas e a produção foram alterados, significativamente em função da aplicação superficial de calcário, sendo que melhores respostas da planta foram obtidas com saturação por bases de aproximadamente $50 \%$.

Termos para indexação: acidez do solo, calagem superficial, Citrus sinensis, V\%.

\section{SURFACE LIMING APPLICATION IN THE SOIL WITHADULT ORANGE CV.PÊRA}

ABSTRACT: The state of São Paulo has the largest citriculture of the world, managements are of extreme importance and seek to increase and improve the production. Because of that, an experiment with application of five limestone rates was installed in EECB (Bebedouro, SP, Brazil), in a Hapluxtox (Red Latossol), in July/99. The effects of the limestone, after its application were evaluated through soil testing, in the layers $0-10,10-20,20-40$ and $40-60 \mathrm{~cm}$, at the $6,12,18,24,30$ and 36 months. Linear models demonstrated that the effects of surface liming in soil could reach up $20-40 \mathrm{~cm}$. It is known that soil base saturation is a great property of liming action, although it is necessary to use more soil parameters to evaluate its effects. In soils with base saturation $>50 \%$ the limestone application can be reduce. The maximum reaction of limestone happened between the 12 and 18 months after its application, but in areas with perennial cultures the relative studies to the effects of the liming should be longer.

Index terms: soil acidity, surface liming, Citrus sinensis, base saturation.

\section{INTRODUÇÃO}

O Brasil é responsável por $28 \%$ do volume de frutas cítricas no mundo (ABECITRUS, 2006), sendo que a área citrícola do País é de aproximadamente 800 mil de hectares (IBGE, 2006), porém a produtividade dos pomares é baixa devido, entre outros fatores, a aspectos ligados à acidez dos solos.

É conhecida a importância da calagem para a melhoria das condições bio-físico-químicas dos solos, sendo estas refletidas pelas plantas através do aumento dos lucros obtidos com a atividade citrícola (Boaretto et al., 1996). Essa prática é de fundamental importância em solos ácidos, tornando-se indispensável na maioria dos casos (Quaggio, 1992); porém, nem sempre é realizada, ou o é de modo inadequado e, portanto, ineficaz.

Em culturas perenes em produção, a incorporação de corretivos da acidez (com grade, arado ou outro implemento) é complexa, devido às características intrínsecas dessas culturas $\mathrm{e}$ à falta de informações científicas e técnicas (Quaggio, 1986). Nessas situações, a mobilização mecânica do solo em profundidade fica comprometida, devido aos riscos de danos ao sistema radicular das plantas (Vitti et al., 1996). Além disso, as injúrias causadas às raízes pelo uso de implementos podem agravar os problemas fitossanitários delas decorrentes.

Boaretto et al. (1996) fizeram uma análise crítica das recomendações oficiais feitas nos diferentes estados brasileiros sobre calagem para a cultura do citros, confrontando-as com os resultados de pesquisas disponíveis na literatura nacional. Os autores concluíram que a maioria das recomendações encontradas nos boletins oficiais carecem de embasamento experimental, pois o número de trabalhos de pesquisa sobre o assunto é muito reduzido. Além disso, aspectos como época de aplicação e

\footnotetext{
1(Trabalho 187-06). Recebido em 17-11-2006. Aceito para publicação em : 10-08-2007. Parte da dissertação de mestrado do primeiro autor apresentada ao Programa de Pós-Graduação em Agronomia (Ciência do Solo) da FCAV/Unesp. Pesquisa financiada pela FAPESP (processo $\left.{ }^{\circ}{ }^{00} / 09964-2\right)$.

${ }^{2}$ Universidade Estadual de Mato Grosso do Sul, Unidade Universitária de Aquidauana, Rod. Aquidauna/Piraputanga, km 12, CEP 79200-000 Aquidauana-MS. camacho@uems.br

${ }^{3}$ FCAV/Unesp-Jaboticabal, Dep. de Solos e Adubos, Via de Acesso Prof. Paulo Donato Castellane s/nº, CEP 14884-900 Jaboticabal-SP. E-mail: natale@fcav.unesp.br, rmprado@fcav.unesp.br, andrioli@fcav.unesp.br

${ }^{4}$ Bolsista de Produtividade em Pesquisa do CNPq

${ }^{5}$ Universidade Federal do Ceará, Centro de Ciências Agrárias, Departamentode Fitotecnia. Campus do Pici, CEP 60356-001, Fortaleza-CE. mcleber@ufc.br

${ }^{6}$ Embrapa Mandioca e Fruticultura. Rod. Brigadeiro Faria Lima, km 384, CEP 14170000 Bebedouro-SP. E-mail: stuchi@estacaoexperimental.com.br
} 
incorporação de corretivo, não apresentam resultados específicos para a cultura de citros na literatura consultada, concordando com Vitti et al. (1996).

Diante desse contexto, o presente trabalho teve por objetivo estudar os efeitos da aplicação de calcário calcinado ao solo, sem incorporação, acompanhando sua movimentação no perfil ao longo do tempo e determinando seus benefícios à cultura dos citros, avaliados através das propriedades do solo, especialmente $\mathrm{pH}$ e saturação por bases, o estado nutricional e a produção de um pomar adulto de laranjeira Pêra.

\section{MATERIAL E MÉTODOS}

O experimento foi implantado em julho de 1999, no município de Bebedouro-SP, na Estação Experimental de Citricultura de Bebedouro (EECB). O solo da área é um Latossolo Vermelho distrófico típico, textura média, A moderado, álico (Hapluxtox). Amostragens foram realizadas nas camadas de 0-10; $10-20 ; 20-40$ e 40-60 cm, na linha da cultura (projeção da copa) e na entrelinha do pomar (entre copas), antes da instalação do ensaio. Os resultados das análises químicas, para fins de fertilidade do solo, encontram-se na Tabela 1.

O pomar foi implantado em dezembro de 1985, sendo utilizada como copa a laranjeira Pêra (Citrus sinensis L. Osbeck) e como porta-enxerto a tangerina Cleópatra (Citrus reshni Hort. ex tan), em espaçamento de $7 \times 5 \mathrm{~m}$.

O delineamento experimental adotado foi em blocos casualizados, com cinco repetições. Os tratamentos consistiram da aplicação superficial de cinco doses de calcário calcinado $(0$; 0,$552 ; 1,104 ; 1,656$ e $\left.2,208 \mathrm{tha}^{-1}\right)$. A dose calculada de $1,104 \mathrm{tha}^{-1}$ é a recomendada para elevar a saturação por bases a 70\% (GRUPO PAULISTADE ADUBAÇÃO DE CITROS, 1996).

Utilizou-se o calcário calcinado com PRNT igual a 131\%, contendo $42 \%$ de $\mathrm{CaO}$ e $25 \% \mathrm{MgO}$. A granulometria foi determinada, utilizando-se de peneiras ABNT n ${ }^{\circ} 10 ; 20$ e 50, que retiveram zero, 1 e $9 \%$ do corretivo, respectivamente.

O calcário foi aplicado manualmente, em ambos os lados da planta, numa faixa de $2,5 \mathrm{~m}$ da base do tronco da árvore, perfazendo $5 \mathrm{~m}$ de largura na direção da entrelinha e linha da cultura. Assim, nas entrelinhas da cultura, restou apenas uma faixa contínua de $2 \mathrm{~m}$ (entre copas), em que não foi aplicado o corretivo.

As parcelas experimentais foram compostas por cinco plantas, sendo consideradas as três centrais como árvores úteis para as avaliações. A fim de minimizar as eventuais interferências, as linhas nas quais foram aplicados os tratamentos foram ladeadas por linhas de bordadura, conforme recomendado por Pearce (1976), citado por Rosand \& Santana (1991).

A adubação, durante todo o período experimental, foi realizada, tendo-se como base as recomendações do GRUPO PAULISTA DE ADUBAÇÃO DE CITROS (1996). As doses de fertilizantes foram aplicadas em três parcelas anuais (set/out, dez/ jan e mar/abr), sendo distribuídas em toda a volta da planta, em uma faixa de aproximadamente $0,5 \mathrm{~m}$ de largura, na projeção da copa (entre 1,5 $\mathrm{m} \mathrm{e} \mathrm{2,0} \mathrm{m}$ da base do tronco), o mesmo local onde, com o decorrer do experimento, foram retiradas as amostras para análise química para fins de fertilidade do solo.

As amostragens de solo nas camadas de $0-10 ; 10-20$ e 20 $40 \mathrm{~cm}$ foram realizadas aos $6 ; 12 ; 18 ; 24 ; 30$ e 36 meses, enquanto, na camada de $40-60 \mathrm{~cm}$, as amostragens deram-se aos $18 ; 24 ; 30 \mathrm{e}$ 36 meses. Foram coletadas 4 subamostras por planta útil (uma subamostra em cada quadrante), num total de 12 por parcela, a fim de constituir uma amostra composta. As amostras foram retiradas a uma distância de aproximadamente 1,5 a 2,0 m da base da planta. As determinações químicas nas amostras de solo seguiram os métodos preconizados por Raij et al. (2001).

As colheitas foram realizadas nos meses de julho/agosto (colheita principal), sendo depois adicionadas produções extemporâneas, pois a variedade Pêra tende a produzir frutos durante todo o ano.

Preliminarmente, ajustaram-se equações por análise de regressão múltipla, sendo feita a escolha dos parâmetros do modelo com base nos níveis de significância do teste $\mathrm{F}$ e do teste $\mathrm{T}$.

\section{RESULTADOS E DISCUSSÃO}

A análise de variância, apresentada de forma resumida através da probabilidade de $\mathrm{F}$, permite verificar quais propriedades foram alteradas pela calagem (Tabela 2). A soma das camadas de 0-10 e 10-20 cm representa a camada arável de onde são retiradas as amostras de solo normalmente utilizadas em análises químicas para fins de fertilidade; logo, alterações nessas duas camadas demonstram a eficiência da calagem superficial como modificadora do ambiente abrangido pela camada arável. Resultados da eficiência da calagem superficial sobre características químicas da subsuperfície, em áreas com culturas perenes, foram relatados por Chaves et al. (1984) e Pavan (1994).

As alterações na camada de $20-40 \mathrm{~cm}$ demonstram que o movimento do calcário atingiu essa camada, alterando $\mathrm{pH}, \mathrm{Ca}$, $\mathrm{Mg}, \mathrm{H}+\mathrm{Al}$, SB e V\%. Não houve, porém, neutralização do Al. Vários mecanismos podem estar envolvidos na neutralização dos componentes da acidez em profundidade, a partir da calagem superficial. Os mecanismos propostos para solos sob plantio direto envolvem, na maioria das vezes, quantidades elevadas de resíduos orgânicos na superfície (Sidiras \& Pavan, 1985; Oliveira \& Pavan, 1996; Caires et al., 2000). Porém, na cultura da laranja, a quantidade de resíduos vegetais é muito pequena, quando comparada ao plantio direto, o que poderia explicar a atuação efetiva na neutralização do alumínio somente até a camada de 10$20 \mathrm{~cm}$ no pomar. Entretanto, a neutralização da acidez na camada de 20-40 cm foi parcial, pois, embora as concentrações de $\mathrm{Al}$ não tenham sido alteradas, a acidez potencial revelou modificações nessa camada (Tabela 2).

A movimentação do Ca e do $\mathrm{Mg}$ pode ser explicada pela complexação orgânica desses cátions (Franchini et al., 1999; Franchini et al., 2001); porém, essa complexação depende, também, de resíduos vegetais na superfície do solo. Miyazawa et al. (1992) afirmam que o Al também pode ser complexado, enquanto Miyazawa et al. (1993) relatam que os ácidos orgânicos podem modificar os valores de $\mathrm{pH}$ em função do potencial de neutralização do hidrogênio. Essa contradição (aumento dos valores de $\mathrm{pH}$ e das concentrações de $\mathrm{Ca}$ e $\mathrm{Mg}$ sem alterações na 
concentração de Al) indica que a atuação dos ácidos orgânicos pode ser variável em função das próprias características do solo.

$\mathrm{O}$ efeito quadrático observado na camada de $0-10 \mathrm{~cm}$ (Figura 1a) é o que melhor representa o ambiente estudado, pois, com o aumento das doses de calcário, os valores de saturação por bases do solo cresceram. Observações semelhantes foram feitas por Caires et al. (2000) em área sob plantio direto. Os valores de $\mathrm{V}$ atingiram cerca de $70 \%$ na maior dose, já que, no complexo de troca dos colóides do solo, há íons hidrogênios retidos por ligações co-valentes, que dificilmente serão deslocados.

Na camada de 10-20 cm, observou-se uma ação crescente do calcário, sendo visível (Figura 1b) o efeito das doses aplicadas sobre a saturação por bases do solo. Na Figura 1, é possível observar a inclinação do gráfico referente ao efeito da calagem, a qual é bem acentuada na camada de $10-20 \mathrm{~cm}$, com valores de saturação por bases estimados entre 37 e $47 \%$ aos 36 meses, enquanto, na camada de $20-40 \mathrm{~cm}$, esses valores estão no intervalo de 26 a $28 \%$, aproximadamente.

Na camada de 40-60 cm, a análise estatística não detectou diferenças significativas, supondo-se então que o calcário aplicado superficialmente não atingiu essa camada, passados 36 meses da aplicação (Figura 1). Esse fato está relacionado à dinâmica de reação do calcário, pois, sendo ele composto por partículas finas, como indicado pela sua granulometria, passou pelas camadas anteriores, reagindo nas mesmas e alterando-as.

Como existe alta correlação entre $\mathrm{pH}$ e saturação por bases (Catani \& Gallo, 1955; Raij et al., 1968) e dessas duas características

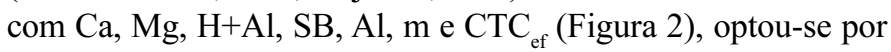
detalhar o comportamento da saturação por bases, extrapolandose as afirmações para as demais características.

A correlação entre $\mathrm{pH} \mathrm{e} \mathrm{V \%} \mathrm{nos} \mathrm{solos} \mathrm{cultivados} \mathrm{é} \mathrm{devida,}$ principalmente, ao fato de que mudanças no $\mathrm{pH}$ estão associadas a aplicações de carbonatos de cálcio e magnésio que, além de diminuírem a acidez ativa $(\mathrm{pH})$, potencial $(\mathrm{H}+\mathrm{Al})$ e trocável $(\mathrm{Al})$, fornecem cátions trocáveis $(\mathrm{Ca}$ e $\mathrm{Mg})$ para o solo, aumentando, assim, a soma de bases e, conseqüentemente, a saturação por bases.

A ação da calagem em função do tempo após a aplicação mostrou-se significativa para várias características do solo (Tabela 3).

As alterações ocorridas nas concentrações de $\mathrm{P}$ e $\mathrm{K}$ do solo devem-se à adubação realizada, pois, com a valorização da laranja no mercado, a quantidade de adubo utilizada foi maior, seguindo as recomendações do GRUPO PAULISTA DE ADUBAÇÃO DE CITROS (1996). Além disso, a calagem tende a melhorar o ambiente químico do solo, proporcionando condições favoráveis à absorção desses nutrientes pelas plantas, de acordo com o relatado por vários autores (Leal \& Veloso, 1973; Defelipo \& Braga, 1983; Goedert et al., 1986; Natale \& Coutinho, 1994).

Na camada de $0-10 \mathrm{~cm}$, a calagem superficial proporcionou alterações em todas as amostragens realizadas, sendo que seu efeito diminui linearmente a partir de 12 meses após a aplicação do calcário. Como o estudo foi conduzido por 3 anos, verifica-se que o calcário teve sua máxima reação no primeiro ano após sua aplicação. Esse fato pode ser atribuído ao elevado PRNT do corretivo, que possui uma ação imediata na superfície do solo (camada de 0-10 cm, pois o calcário não foi incorporado) e, com o passar do tempo, essa ação diminui. Outro fator que deve ser levado em consideração, é a hipótese de que o corretivo aplicado pode ter descido para as camadas subseqüentes por fenômenos físicos (através do arraste pela água das chuvas, por exemplo) bem como carreado por efeito da matéria orgânica presente, ainda que em baixa quantidade (fenômenos químicos e biológicos).

O caminhamento, no perfil, do calcário aplicado superficialmente sem incorporação posterior, é gradativo, conforme estudos realizados por Potker \& Ben (1998) e Caires et al. (2000). Sua movimentação vertical depende de vários fatores, tais como: precipitação, textura e porosidade do solo, granulometria e reatividade do calcário, e material vegetal existente no solo ou em sua superfície.

Nas camadas adjacentes (10-20 e 20-40 cm), a saturação por bases apresentou tendências quadráticas (Figura 1). Na camada de 10-20 cm, a máxima reação do calcário ocorreu aos 18 meses após a apolicação superficial do corretivo.

Os teores foliares de $\mathrm{Ca}$ foram alterados em função das doses de calcário nas safras 2000-2001 e 2001-2002, não sendo identificada alteração significativa para a safra 2002-2003 (Figura 3a). Os maiores teores foliares de $\mathrm{Ca}$ foram estimados para as doses de 1,03 e 1,26 t ha-1 nas safras 2000-2001 e 2001-2002, respectivamente, as quais corresponderiam a uma saturação por bases entre 40 e $45 \%$, em média, na camada $0-20 \mathrm{~cm}$. Para os teores foliares de $\mathrm{Mg}$, as alterações só foram significativas para a safra 2001-2002, sendo apresentada uma função linear crescente (Figura 3b). A correlação direta dos teores foliares de $\mathrm{Ca}$ e $\mathrm{Mg}$ com as produtividades dentro de cada ano agrícola não foi detectada pela análise estatística.

A produção de laranjas nas safras 2000-2001, 2001-2002 e 2002-2003 não foi alterada significativamente em função das doses de calcário, sendo suas produtividades de $47 ; 34$ e $13 \mathrm{t} \mathrm{ha}^{-1}$, respectivamente. As produtividades obtidas nos dois primeiros anos agrícolas, ainda que não tenham sido alteradas significativamente pela calagem superficial, estão acima da média nacional, que se situa entre 20 e $25 \mathrm{t} \mathrm{ha}^{-1}$ (IBGE, 2002). A produtividade do ano agrícola 2002-2003 foi baixa devido à influência do clima no período. Ao fazer uso da produção acumulada das safras 2000-2001 e 2001-2002, foi estimada uma tendência quadrática (Figura 4), cujo ponto de máxima eficiência técnica foi calculado em aproximadamente $0,3 \mathrm{t} \mathrm{ha}^{-1}$. Tal comportamento sugere que a saturação por bases indicada para a cultura pode ser inferior àquela preconizada pelo GRUPO PAULISTA DE ADUBAÇÃO DE CITROS (1996), pois, antes da calagem, a saturação por bases do solo já se encontrava, na região da projeção da copa, em 58 e 56\% nas camadas de 0-10 e 10-20 cm, respectivamente. Resultados semelhantes foram obtidos por Anjos (1997), em estudo de calagem por um ano, sendo diferente dos resultados encontrados por Quaggio (1991) em experimento conduzido por seis anos. Amaral (1989) e Paro (1991) encontraram resposta sobre a produção de laranja no terceiro ano após a calagem. O pomar estudado por esses autores, porém, não se encontrava na fase adulta. Nessa situação, respostas na produção de frutos tendem a ser variáveis, pois o metabolismo de plantas adultas difere daquele de plantas jovens (Salisbury \& Ross, 1991). As repostas das plantas perenes, como frutíferas, 
demandam tempo, pois as alterações são gradativas e no sentido: propriedades do solo $\mathrm{P}$ teores foliares de nutrientes $\mathrm{P}$ produção e qualidade de frutos.

TABELA 1 - Resultado da análise química do solo antes da instalação do experimento

\begin{tabular}{|c|c|c|c|c|c|c|c|c|c|c|c|}
\hline Camada & $\begin{array}{c}\mathrm{pH} \\
\mathrm{CaCl}_{2} \\
\end{array}$ & M.O. & $\begin{array}{c}\mathbf{P} \\
\text { (resina) }\end{array}$ & K & $\mathrm{Ca}$ & $\mathrm{Mg}$ & $(\mathrm{H}+\mathrm{Al})$ & Al & SB & $\mathrm{T}$ & V \\
\hline & & \multicolumn{9}{|c|}{ Projeção da copa } & $\%$ \\
\hline $0-10 \mathrm{~cm}$ & 5,4 & 14 & 20 & 1,5 & 17 & 9 & 20 & 0 & 27,5 & 47,5 & 58 \\
\hline $10-20 \mathrm{~cm}$ & 5,3 & 14 & 6 & 0,7 & 17 & 9 & 21 & $\mathrm{O}$ & 26,7 & 47,7 & 56 \\
\hline $20-40 \mathrm{~cm}$ & 4,8 & 12 & 3 & 0,4 & 13 & 7 & 28 & 5 & 20,4 & 48,4 & 42 \\
\hline $40-60 \mathrm{~cm}$ & 4,5 & 10 & 3 & 0,2 & 8 & 4 & 34 & 9 & 12,2 & 46,2 & 26 \\
\hline \multicolumn{12}{|c|}{ "Entre copas" } \\
\hline $0-10 \mathrm{~cm}$ & 5,9 & 14 & 4 & 0,4 & 28 & 12 & 11 & $\mathrm{O}$ & 40,4 & 51,4 & 79 \\
\hline $10-20 \mathrm{~cm}$ & 5,8 & 12 & 5 & 0,3 & 25 & 13 & 12 & 0 & 38,3 & 50,3 & 76 \\
\hline $20-40 \mathrm{~cm}$ & 5,8 & 12 & 3 & 0,3 & 17 & 8 & 17 & 0 & 25,3 & 42,3 & 60 \\
\hline $40-60 \mathrm{~cm}$ & 4,4 & 10 & 2 & 0,3 & 6 & 3 & 31 & 7 & 9,3 & 40,3 & 23 \\
\hline
\end{tabular}

TABELA 2 -Resumo da análise de variância para as características do solo em função das doses de calcário

\begin{tabular}{|c|c|c|c|c|c|c|c|c|c|c|c|c|c|}
\hline Camada & $\mathrm{pH}$ & M.0. & $\mathrm{P}$ & K & $\mathrm{Ca}$ & $\mathrm{Mg}$ & $\mathrm{H}+\mathrm{Al}$ & SB & CTC & V & $\mathrm{Al}$ & $\mathrm{m}$ & $\mathrm{CTC}_{\mathrm{ef}}$ \\
\hline $\mathrm{cm}$ & \multicolumn{13}{|c|}{ Probabilidade de F } \\
\hline $0-10$ & $<0,01$ & 0,22 & 0,24 & 0,78 & $<0,01$ & $<0,01$ & $<0,01$ & $<0,01$ & $<0,01$ & $<0,01$ & $<0,01$ & $<0,01$ & $<0,01$ \\
\hline $10-20$ & $<0,01$ & 0,64 & 0,43 & 0,94 & $<0,01$ & $<0,01$ & $<0,01$ & $<0,01$ & 0,76 & $<0,01$ & $<0,01$ & $<0,01$ & $<0,01$ \\
\hline $20-40$ & 0,01 & 0,50 & 0,30 & 0,85 & 0,05 & 0,02 & 0,04 & 0,02 & 0,55 & 0,03 & 0,15 & 0,07 & 0,02 \\
\hline $40-60$ & 0,35 & 0,90 & 0,38 & 0,28 & 0,54 & 0,51 & 0,71 & 0,54 & 0,54 & 0,56 & 0,50 & 0,49 & 0,71 \\
\hline
\end{tabular}
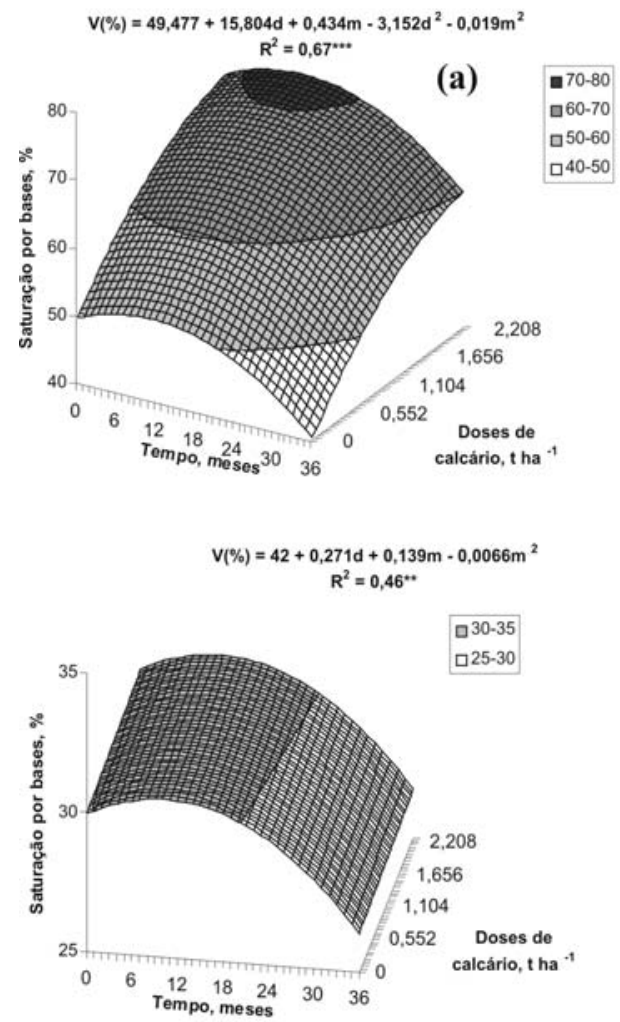

TABELA 3 - Resumo da análise de variância para as características do solo em função do tempo decorrido após a calagem superficial.

\begin{tabular}{|c|c|c|c|c|c|c|c|c|c|c|c|c|c|}
\hline Camada & $\mathrm{pH}$ & M.O. & P & K & $\mathrm{Ca}$ & $\mathrm{Mg}$ & $\mathrm{H}+\mathrm{Al}$ & SB & CTC & V & $\mathrm{Al}$ & $\mathrm{m}$ & $\mathrm{CTC}_{\mathrm{ef}}$ \\
\hline $\mathrm{cm}$ & \multicolumn{13}{|c|}{ Probabilidade de F } \\
\hline $0-10$ & $>0,01$ & $>0,01$ & 0,82 & $>0,01$ & 0,01 & $>0,01$ & $>0,01$ & $>0,01$ & $>0,01$ & 0,51 & 0,22 & 0,21 & $>0,01$ \\
\hline $10-20$ & $>0,01$ & $>0,01$ & $>0,01$ & $>0,01$ & 0,06 & $>0,01$ & 0,01 & 0,18 & $>0,01$ & 0,75 & 0,23 & 0,12 & 0,27 \\
\hline $20-40$ & $>0,01$ & $>0,01$ & $>0,01$ & $>0,01$ & $>0,01$ & $>0,01$ & $>0,01$ & 0,05 & $>0,01$ & 0,02 & 0,95 & 0,38 & $>0,01$ \\
\hline $40-60$ & $>0,01$ & 0,45 & $>0,01$ & $>0,01$ & $>0,01$ & $>0,01$ & 0,03 & 0,19 & $>0,01$ & 0,48 & 0,31 & 0,35 & $>0,01$ \\
\hline
\end{tabular}
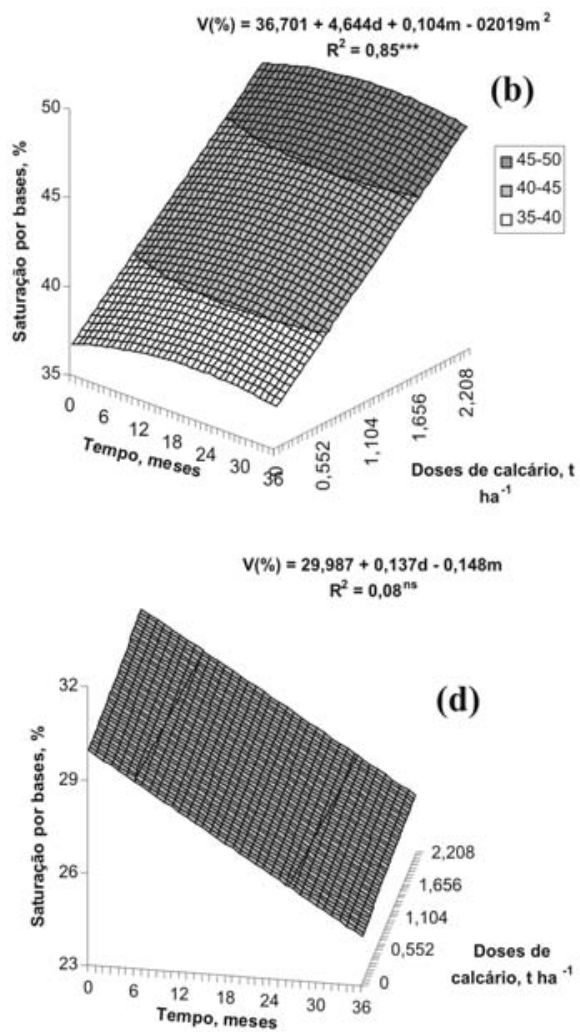

FIGURA 1 - Alterações na saturação por bases em diferentes profundidades do solo, considerando as doses de calcário e o tempo decorrido após a aplicação superficial nas camadas de (a) 0-10, (b) 10-20, (c) 20-40 e (d) 40-60 cm. ***,** e ${ }^{\text {ns }}$ representam modelos significativos a 0,001, 1 e $5 \%$ de probabilidade e não significativo, respectivamente. 

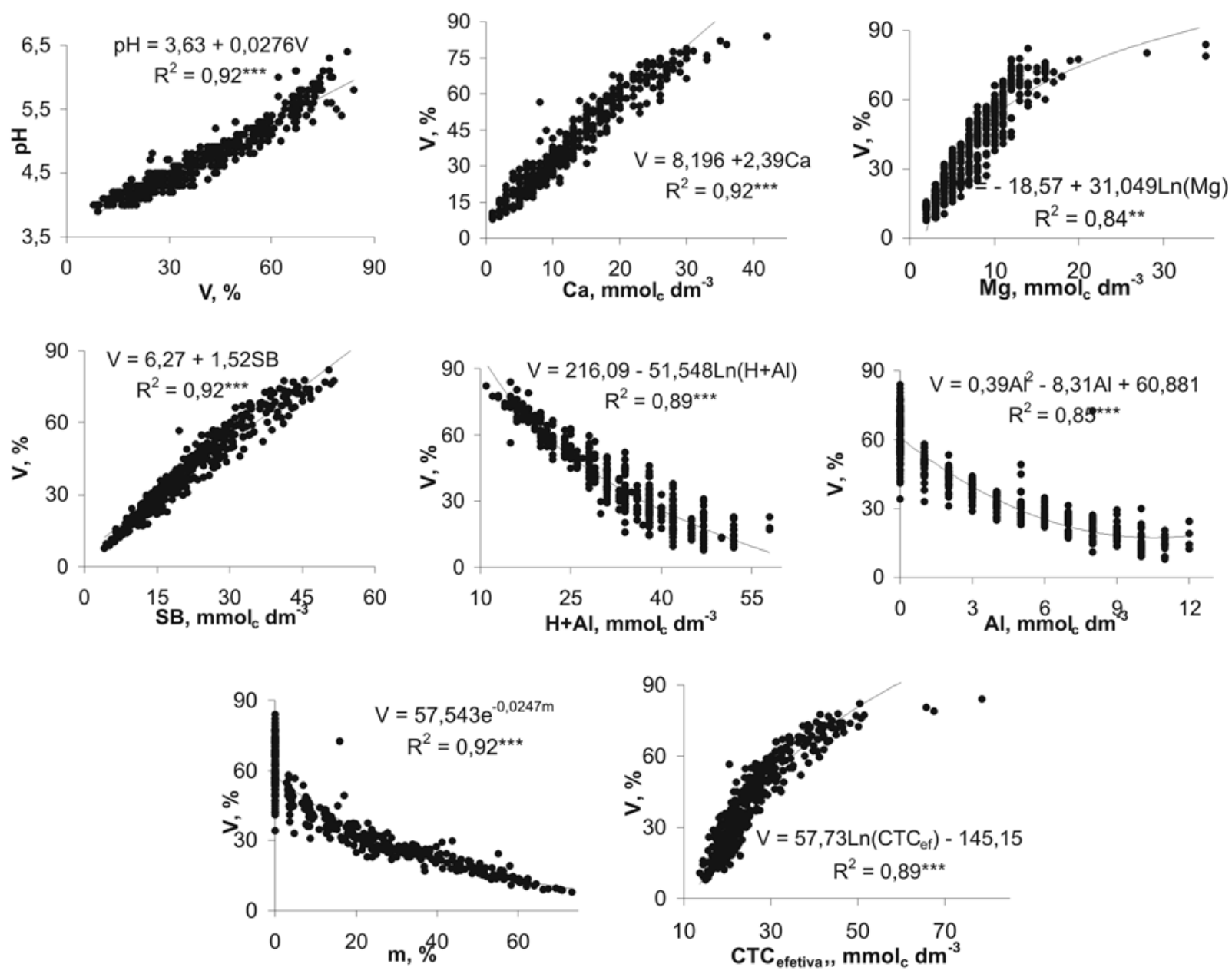

FIGURA 2 - Correlações existentes entre $\mathrm{pH}, \mathrm{Ca}, \mathrm{Mg}, \mathrm{SB}, \mathrm{H}+\mathrm{Al}, \mathrm{Al}, \mathrm{m} \mathrm{e}^{\mathrm{CTC}} \mathrm{ef}_{\text {ef }}$ com os valores de saturação por bases no solo. ***, $* *,{ }^{*} \mathrm{e}^{\text {ns }}$ representa modelo significativo a $0,01,1$ e $5 \%$ de probabilidade e não significativo, respectivamente.
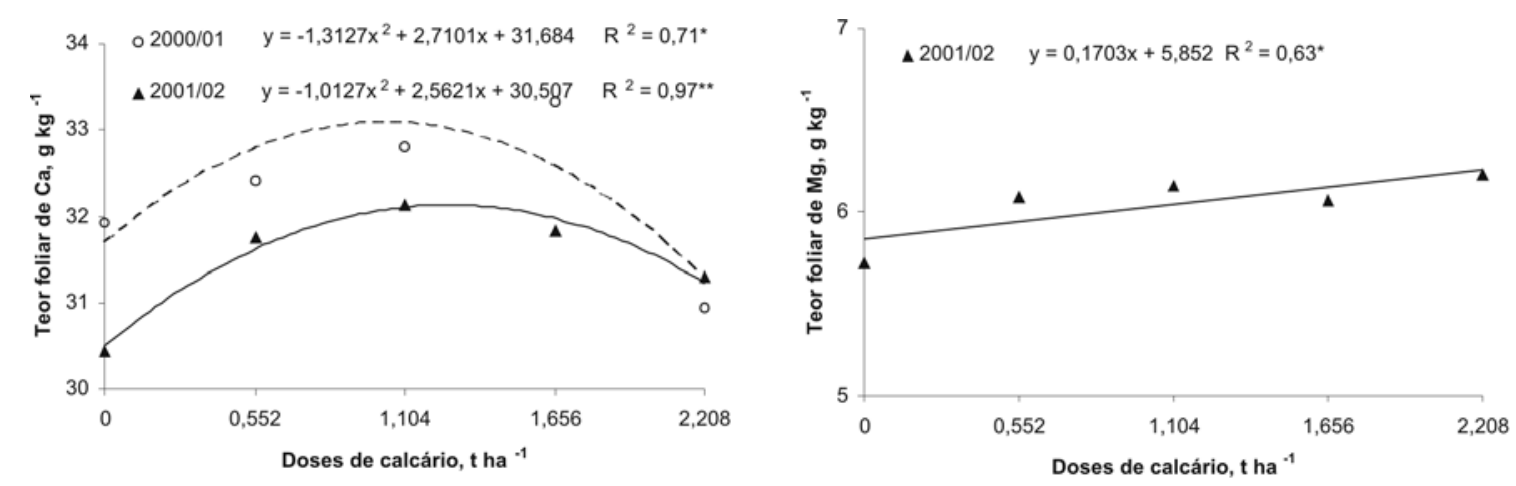

FIGURA 3 - Teores foliares de $\mathrm{Ca}$ (a) e $\mathrm{Mg}$ (b) em pomar adulto de laranjeira Pêra em função de doses crescentes de calcário aplicados superficialmente. 


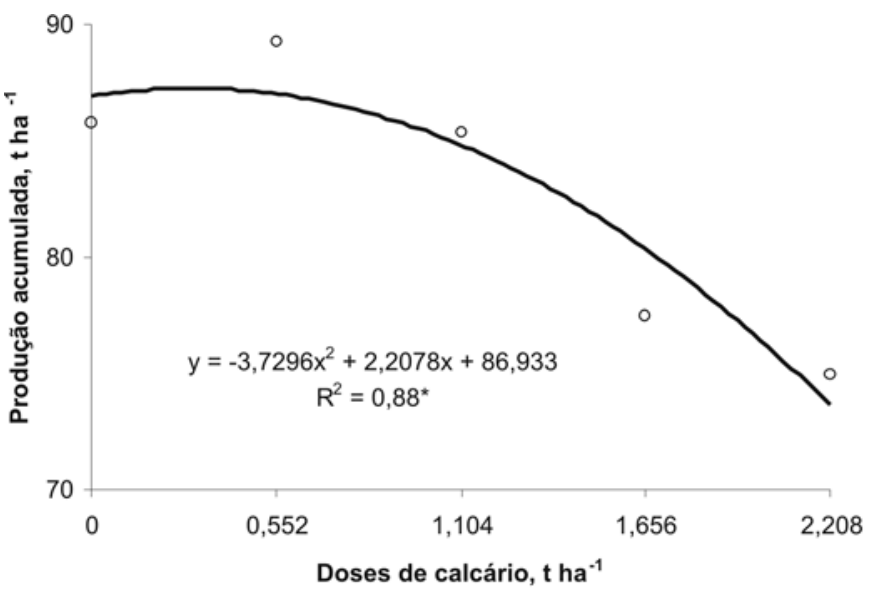

FIGURA 4 - Produção acumulada nas safras 2000-2001 e 20012002 em função de doses crescentes de calcário aplicados superficialmente em pomar adulto de laranjeira Pêra.

\section{CONCLUSÕES}

1-A aplicação superficial de calcário alterou a saturação por bases, bem como o ambiente químico do solo nas camadas de $0-10 ; 10-20$ e $20-40 \mathrm{~cm}$.

2-Pelos resultados obtidos, o período compreendido entre 12 e 18 meses foi aquele no qual ocorreu a máxima reação do calcário calcinado nas camadas subsuperficiais.

3-O estado nutricional das plantas e a produção foram alterados significativamente, sendo que a produtividade acumulada indica a saturação por bases ideal para a cultura da laranja em torno de $50 \%$.

\section{REFERÊNCIAS}

ABECITRUS. Produção de laranja. Disponível: <http:// www.abecitrus.com.br/produção_br.html $>$. Acesso em : 28 ago. 2006.

ALVES, H.M.R.; LOPES, A.S. Efeito de corretivos e fertilizantes na redução da percentagem de saturação de alumínio nas camadas sub-superficiais de solos sob cerrado. In: CONGRESSO BRASILEIRO DE CIÊNCIA DO SOLO, 18., 1981, Salvador. Resumos... Salvador: SBCS/Governo da Bahia, 1981. p. 95-96.

BOARETTO, A.E.; MURAOKA, T.; REGO, C..I. Calagem e gessagem em citricultura. In: SEMINÁRIO INTERNACIONAL DE CITROS, 4, 1996, Bebedouro. Anais... Campinas: Fundação Cargill, 1996. p. 115-129.

BRAMS, E.A. Continuous cultivation of West African soils: organic matter diminution and effects of applied lime and phosphorus. Plant and Soil, Dodrecht, v.35, p.401-414, 1971.
CAIRES, E.F.; BANZATTO, D.A.; FONSECA, A.F. Calagem na superfície em sistema plantio direto. Revista Brasileira de Ciência do Solo, Campinas, v.24, p.161-169, 2000.

CAMARGO, A.P.; RAIJ, B.van; CANTARELLA, H.; ROCHA, T.R.; NAGAI, V.; MASCARENHAS, H.A.A. Efeito da calagem nas produções de cinco cultivos de milho, seguidos de algodão e soja. Pesquisa Agropecuária Brasileira, Brasília, v.17, p.1007$1012,1982$.

CATANI, R.A.; GALLO, J.R. Avaliação da exigência de calcário dos solos de São Paulo mediante a correlação entre o $\mathrm{pH}$ e a saturação por bases. Revista de Agricultura, Piracicaba, v.30, p.49-60, 1955 .

CHAVES, J.C.D.; PAVAN, M.A.; IGUE, K. Resposta do cafeeiro à calagem. Pesquisa Agropecuária Brasileira, Brasília, v.19, p.573582,1984 .

DEFELIPO, B.V.; BRAGA, J.M. Influência da calagem e fontes de potássio na adsorção de potássio em latossolos em Minas Gerais. Revista Brasileira de Ciência do Solo, Campinas, v.7, p.119-122, 1983.

FAO. PRODUCTION YEARBOOK, Roma, v. 52, p. 55-6, 157-8, 1999.

FRANCHINI, J.C.; GONZALEZ-VILA, F.J.; CABRERA, F.; MIYAZAWA, M.; PAVAN, M.A. Rapid transformations of plant water-soluble organic compounds in relation to cation mobilization in an acid Oxisol. Plant and Soil, Dordrecht, v.231, p.55-63, 2001.

FRANCHINI，J.C.; MIYAZAWA，M.; PAVAN，M.A.; MALAVOLTA, E. Dinâmica de íons em solo ácido lixiviado com extratos de resíduos de adubos verdes e soluções puras de ácidos orgânicos. Pesquisa Agropecuária Brasileira, Brasília, v.34, p.2267-2276, 1999b.

GOEDERT, W.J.; SOUZA, D.M.G.; LOBATO, E. Fósforo. In: GOEDERT, W.J. (Ed.). Solos dos cerrados: tecnologia e estratégias de manejo. São Paulo: Nobel, 1986. p.129-126.

Citros: laranja, limão, tangerina e murcote. In: RAIJ, B. Van; CANTAELlA, H.; QUAGGIO, J.A.; FURLANI, A.M.C. Recomendações de adubação e calagem para o estado de São Paulo. 2.ed. Campinas: Instituto Agronômico, 1996. p. 133-136.

IBGE. Área: confronto das estimativas julho/julho 2006. Disponível em: $<\mathrm{http}: / / \mathrm{www}$.ibge.gov.br $>$. Acesso em: 28 ago. 2006.

LEAL, J.R.; VELLOSO, A.C.X. Adsorção de fosfato em latossolos sob vegetação de cerrado. Pesquisa Agropecuária Brasileira, Brasília, v.8, p.81-88, 1973. 
MIYAZAWA, M.; PAVAN, M.A;, CALEGARI, A. Efeito de material vegetal na acidez do solo. Revista Brasileira de Ciência do Solo, Campinas, v.17, p.411-416, 1993.

NATALE, W.; COUTINHO, E.L.M. Avaliação da eficiência agronômica de frações granulométricas de um calcário dolomítico. Campinas: Revista Brasileira de Ciência Solo, Campinas, v.18, p.55-62, 1994.

OLIVEIRA, E.L.; PAVAN, M.A. Control of soil acidity in no-tillage system for soybean production. Soil Tillage Research, Amsterdan, v.38, p.47-57, 1996.

PARO, M. Efeitos da aplicação de calcário dolomítico calcinado, gesso e misturas calcário/gesso na cultura do citros em produção. 1991. 64 f. Monografia (Trabalho de Graduação em Agronomia) - Faculdade de Ciências Agrárias e Veterinárias, Universidade Estadual Paulista, Jaboticabal, 1991.

PAVAN, M.A. Movimentação de calcário no solo através de técnicas de manejo da cobertura vegetal em pomares de macieira. Revista Brasileira de Fruticultura, Jaboticabal, v.16, p.86-91, 1994.

POTTKER, D.; BEN, J.R. Calagem para uma rotação de culturas no sistema plantio direto. Revista Brasileira de Ciência do Solo, Campinas, v.22, p.675-684, 1998.

QUAGGIO, J.A. Conceitos modernos sobre calagem e adubação para citros no estado de São Paulo. Laranja, Cordeirópolis, v. 13, n. 2, p. 457-488, 1992.
QUAGGIO, J.A. Métodos de aplicação do calcário em culturas anuais e perenes. In: SIMPÓSIO SOBRE APLICAÇÃO DE CALCÁRIO NA AGRICULTURA, 1986, Campinas. Anais... Campinas: Fundação Cargill, 1986. p.21.

RAIJ, B. van; SACCHETTO, M.T.D.; IGUE, T. Correlações entre o pH e o grau de saturação em bases nos solos com horizontes B textural e horizonte B latossólico. Bragantia, Campinas, v.27, p.193200,1968

RAIJ, B. van; ANDRADE, J.C.; CANTARELLA, H.; QUAGGIO, J.A. (Ed.) Análise química para avaliação da fertilidade de solos tropicais. Campinas: Instituto Agronômico, 2001.285 p.

ROSAND, P.C.; SANTANA, M.B.M. Experimentos com adubação em culturas perenes. In: OLIVEIRA, A.J., et al. (Coord.). Métodos de pesquisa em fertilidade do solo. Brasília: EMBRAPA-SEA, 1991. $232 p$.

SIDIRAS, N.; PAVAN, M.A. Influência do sistema de manejo do solo no seu nível de fertilidade. Revista Brasileira de Ciência do Solo, Campinas, v.9, p.249-254, 1985.

VITTI, G.C.; LUZ, P.H.C.; LEÃO, H.C.; SILVA, M.M. Técnicas de utilização de calcário e gesso na cultura dos citros. In: SEMINÁRIO INTERNACIONAL DE CITROS, 4., 1996, Bebedouro. Anais... Campinas: Fundação Cargill, 1996. p. 131-160. 